\title{
ADUBAÇÃO NITROGENADA NA SEVERIDADE DE DOENÇAS FOLIARES, PRODUTIVIDADE E RESPOSTAS BIOQUÍMICAS EM HÍBRIDOS DE MILHO
}

\author{
JAÍZA FRANCISCA RIBEIRO CHAGAS ${ }^{1}$, GIL RODRIGUES DOS SANTOS ${ }^{1}$, \\ RODRIGO VERAS DA COSTA ${ }^{2}$, JOHNATHAN FONTES ALVES ${ }^{1}$ \\ e ILDON RODRIGUES DO NASCIMENTO ${ }^{1}$
}

${ }^{1}$ Univerdidade Federaldo Tocantins, Gurupi-TO,Brasil,
jafra@uft.edu.br, gilsan@uft.edu.br, johnathanhaste@uft.edu.br, ildon@mail.uft.edu.br
${ }^{2}$ Embrapa Milho e Sorgo, Sete Lagoas-MG,Brasil,rodrigo.veras@embrapa.br

Revista Brasileira de Milho e Sorgo, v.17, n.1, p. 1-14, 2018

\begin{abstract}
RESUMO - O nitrogênio participa de muitos processos metabólicos relacionados aos mecanismos de defesa das plantas, podendo além de beneficiar diretamente a produtividade, auxiliar na tolerância a doenças. Objetivou-se avaliar o efeito da adubação nitrogenada de cobertura na severidade de doenças foliares, na produtividade e nas respostas bioquímicas em híbridos de milho. Dois experimentos foram conduzidos em campo, com delineamento experimental de blocos casualizados, com tratamentos dispostos em arranjo de parcelas subdivididas, com três repetições. As parcelas foram constituídas pelos híbridos e as subparcelas, pelas doses de nitrogênio. Determinou-se a área abaixo da curva de progresso da doença (AACPD), a massa de mil grãos (g), a produtividade em $\mathrm{kg} \mathrm{ha}^{-1}$, os teores das enzimas superóxido dismutase (SOD) e catalase (CAT), o aminoácido prolina e os aminoácidos solúveis totais. A maioria dos híbridos avaliados apresentaram resposta a mancha-de-bipolaris e a antracnose-foliar mais severa nas menores doses de nitrogênio testadas (36 e $40 \mathrm{~kg} \mathrm{ha}^{-1}$ ). A ferrugem-polissora foi mais severa em condições de alto nitrogênio para os híbridos ATTACK, TRAKTOR, BM 2202 e 30F53YH. A massa de mil grãos não foi influenciada pelas diferenças nas doses. A produtividade dos híbridos 2B710 e $3 \mathrm{H} 842$ foi maior na dose de $180 \mathrm{~kg} \mathrm{ha}^{-1}$. A catalase e a prolina alcançaram maior e menor atividade, respectivamente, onde ocorreu maior severidade da mancha-de-bipolaris nos híbridos $2 \mathrm{~B} 710$ e AG7088PROX. Os aminoácidos foram encontrados em maiores quantidades nas doses altas de nitrogênio.

Palavras-chave: Zea mays, nutrição, nitrogênio, patógeno, mecanismos de defesa.
\end{abstract}

\section{NITROGEN FERTILIZATION IN LEAF DISEASE SEVERITY, PRODUCTIVITY AND BIOCHEMICAL RESPONSES IN MAIZE HYBRIDS}

\begin{abstract}
Nitrogen participates in many metabolic processes related to the defense mechanisms of plants, besides being able directly to benefit the productivity, to aid in the tolerance to diseases. The objective of this study was to evaluate the effect of nitrogen fertilization on the severity of leaf diseases, productivity and biochemical responses in maize hybrids. Two experiments were conducted in the field, with a randomized complete block design, with treatments arranged in split plot arrangement, and three replications. The plots were composed of the hybrids and the subplots by the nitrogen doses. The area under the disease progress curve (AACPD), one thousand grain mass (g), yield in $\mathrm{kg} \mathrm{ha}^{-1}$, levels of the enzymes superoxide dismutase (SOD) and catalase (CAT), the amino acid proline and the total soluble amino acids were determined. Most of the evaluated hybrids showed a more severe bipolaris spot and foliar anthracnose response at the lowest nitrogen doses tested (36 and $40 \mathrm{~kg} \mathrm{ha}^{-1}$ ). Polissora rust was more severe under high nitrogen conditions for the hybrids ATTACK, TRAKTOR, BM 2202 and 30F53YH. The mass of one thousand grains was not influenced by the differences in the doses. The productivity of the hybrids $2 \mathrm{~B} 710$ and $3 \mathrm{H} 842$ was higher at the dose of $180 \mathrm{~kg} \mathrm{ha}^{-1}$. Catalase and proline reached higher and lower activity, respectively, where the highest severity of the bipolaris spot occurred in hybrids 2B710 and AG7088PROX. Amino acids were found in higher amounts at high doses of nitrogen.
\end{abstract}

Keywords: Zea mays, nutrition, nitrogen, pathogen, defense mechanisms. 
A crescente demanda mundial por alimentos e seus derivados torna o cultivo do milho (Zea mays L.) alvo de diversos estudos visando elevados níveis de produtividade. $\mathrm{O}$ aumento da produção de milho nos últimos anos na região Norte do Brasil é decorrente do melhoramento genético, por meio do desenvolvimento de cultivares mais adaptadas às condições edafoclimáticas, uso de tecnologias empregada no cultivo e também o uso adequado de adubação (Cancellier et al., 2011; Carvalho et al., 2014; Santos et al., 2015).

A exigência nutricional corresponde a um dos fatores mais estudados no cultivo do milho, sendo o nitrogênio o principal nutriente exigido pela cultura, e que tem relação direta com a produtividade de grãos. Esse elemento é responsável por diversas reações fisiológicas, o que torna o seu manejo um dos mais complexos dentre os macronutrientes (Fagan et al., 2007). Além das exigências nutricionais, a produtividade do milho também pode ser influenciada por outros fatores, dentre os quais as doenças se destacam em razão dos danos e perdas ocasionadas à cultura.

Entre as doenças importantes na cultura do milho, vale ressaltar as foliares, que causam danos significativos, em decorrência da destruição dos tecidos foliares e consequentemente da redução de fotoassimilados. Mancha-de-cercospora (Cercospora zea-maydis e C. sorghi f. sp. maydis), mancha-de-bipolaris (Bipolaris spp.), antracnose (Colletotrichum graminicola), ferrugem-comum (Puccinia sorghi), ferrugem-polissora (Puccinia polysora) e a ferrugemtropical (Physopella zeae) são as doenças comumente relatadas causando danos em milho (Lima et al., 2010). O aumento observado da ocorrência destas doenças se dá em razão da ampliação de áreas de safrinhas e maior utilização de irrigação suplementar, práticas que favorecem a sobrevivência de patógenos e o aumento do inóculo para cultivos subsequentes.
As plantas, após o ataque de patógenos, reagem ativando seus mecanismos de defesa. $\mathrm{O}$ nitrogênio participa de muitos processos metabólicos relacionados aos mecanismos de defesa das plantas, e é constituinte essencial na formação de reguladores de crescimento, aminoácidos, proteínas, fitoalexinas e fenóis. As enzimas catalase (CAT) e superóxido dismutase (SOD), por exemplo, apresentam elevada importância na defesa gerada pelas plantas em resposta ao ataque de fungos, atuando na desintoxicação das células das plantas em condições de estresse causado por fungos e insetos (Soares \& Machado, 2007; Shen et al., 2010).

Inúmeros estudos relacionados ao uso do nitrogênio na cultura do milho, em diversas regiões do Brasil, já foram relatados (Carvalho et al., 2013; Mendes et al., 2011; Tomazela et al., 2006). No entanto, há poucos estudos relacionando o uso do nitrogênio ao manejo das doenças foliares no milho e o efeito nas respostas bioquímicas produzidas pela planta (Carvalho et al., 2013; Santos et al., 2013). Neste contexto, objetivou-se com este estudo avaliar o efeito da adubação nitrogenada na severidade das doenças foliares, na produtividade de grãos e nas respostas bioquímicas em diferentes híbridos de milho.

\section{Material e Métodos}

Foram conduzidos dois experimentos em campo na área experimental da Universidade Federal do Tocantins (UFT), Campus de Gurupi, localizada a $11^{\circ}$ $43^{\prime} \mathrm{S}$ e $49^{\circ} 04 \mathrm{~N}^{\prime}$ a $280 \mathrm{~m}$ de altitude. O clima do local é do tipo B1wA' úmido com moderada deficiência hídrica, segundo classificação climática do Sistema Internacional de Köppen (1948). O primeiro experimento foi conduzido no período de janeiro a maio de 
2014 (safra 2013/2014), e o segundo experimento, de dezembro de 2014 a abril de 2015 (safra 2014/2015).

As características químicas do solo da área utilizada nos dois experimentos encontram-se na Tabela 1. Em ambos os experimentos, o sistema de preparo do solo empregado foi o convencional, mediante a utilização de uma aração e duas gradagens, seguida pela sulcagem.

As semeaduras foram realizadas em janeiro de 2014 (safra 2013/2014) e dezembro de 2015 (2014/2015), colocando-se seis sementes por metro linear. Após o desbaste foram mantidas 4,5 sementes/ metro. O delineamento experimental utilizado foi o de blocos completos casualizados, com três repetições. Os tratamentos foram dispostos em arranjado de parcelas subdivididas, com os híbridos nas parcelas e as doses de nitrogênio $(\mathrm{N})$ nas subparcelas. No primeiro experimento foram avaliados os híbridos BRS 1040, BM2202, ATTACK e TRAKTOR. No segundo experimento foram avaliados os híbridos 2B710, 3H842, 30F53YH e AG7088 PROX. As características de cada híbrido constam na Tabela 2. As doses de $\mathrm{N}$ empregadas foram 36 (baixo N) e 160 (alto N) kg ha-1 na safra 2013/2014 e 40 (baixo N) e 180 (alto N) kg ha-1 na safra 2014/2015, utilizando-se como fonte de $\mathrm{N} \mathrm{a}$ ureia. A aplicação das doses de $\mathrm{N}$ foi feita em cobertura, entre as fases de quatro a seis folhas totalmente expandidas e em sulco aberto ao lado das linhas de plantio, o adubo nitrogenado foi coberto posteriormente para evitar perdas por volatilização. As parcelas foram constituídas de quatro linhas de $10 \mathrm{~m}$ de comprimento, espaçadas de $0,7 \mathrm{~m}$ entre si e divididas em subparcelas com $5 \mathrm{~m}$ de comprimento, com média de 4,5 plantas por metro linear. As duas linhas centrais foram consideradas como a área útil das parcelas.

A adubação de base consistiu da aplicação de $450 \mathrm{~kg} \mathrm{ha}^{-1}$ da formulação 5 - 25 - 15 (NPK). Para o controle das plantas invasoras foi aplicada, em pós-emergência, a mistura dos herbicidas atrazina + nicosulfuron, na dose de 5 e 1,5 $\mathrm{L} \mathrm{ha}^{-1}$, respectivamente, seguida de capina manual. $\mathrm{O}$ controle de pragas foi realizado através da aplicação do inseticida metomil na dose de $0,6 \mathrm{~L} \mathrm{ha}^{-1}$.

A colheita foi realizada manualmente, na área útil das parcelas, após a fase de maturação fisiológica dos grãos. Em seguida, efetuou-se a debulha das espigas em trilhadora e foi determinada a umidade dos grãos (\%). Para a obtenção da massa de mil grãos, foram selecionados manualmente e de forma aleatória mil grãos, os quais foram pesados e os valores expressos em gramas. Para a obtenção da produtividade de cada parcela, a massa de grãos foi pesada e a umidade foi corrigida para $13 \%$. Os dados de produtividade foram expressos em $\mathrm{kg} \mathrm{ha}^{-1}$.

As variáveis climáticas precipitação $\left(\mathrm{mm} \cdot \mathrm{dia}^{-1}\right)$, temperaturas máximas e mínimas $\left({ }^{\circ} \mathrm{C}\right)$ e umidade relativa média $(\%)$ foram monitoradas e registradas, durante todo o período de condução dos experimentos, na Estação Meteorológica da Universidade Federal do Tocantins (Figura 1). Durante o período de condução do primeiro experimento, na safra 2013/14, registraram-se temperaturas médias de $26{ }^{\circ} \mathrm{C}$, máxima de $32{ }^{\circ} \mathrm{C}$ e mínima $22{ }^{\circ} \mathrm{C}$; umidade relativa média de $\pm 82 \%$, máxima de $95 \%$ e mínima de $60 \%$ e precipitação total de $763 \mathrm{~mm}$. No período de condução do segundo experimento, safra 2014/2015, foi observada uma grande variação na precipitação ao longo dos meses de dezembro a abril, com precipitação total de $595 \mathrm{~mm}$, temperaturas média de $26^{\circ} \mathrm{C}$, máxima de 32 ${ }^{\circ} \mathrm{C}$ e mínima $22{ }^{\circ} \mathrm{C}$; umidade relativa média de $\pm 83 \%$, máxima de $95 \%$ e mínima de $61 \%$ (Figura 1).

Avaliações das doenças - Para avaliar as doenças foliares, utilizou-se uma escala de notas variando de 1 a 9 , em que $1=0 \%$ de doença; $2=0,5 \%$ área fo- 
Tabela 1. Resultados da análise das propriedades químicas dos solos na camada de 0-20 cm.

\begin{tabular}{lllllllll}
\hline \multirow{2}{*}{ Solo } & \multirow{2}{*}{$\mathbf{~} \mathbf{C a}$} & $\mathbf{M g}$ & $\mathbf{K}$ & $\mathbf{C T C}_{\mathbf{t}}$ & $\mathbf{P}$ & $\mathbf{M . O}$ & $\mathbf{V}$ \\
\cline { 3 - 9 } & & \multicolumn{2}{c}{$\left(\mathrm{cmolc} \mathrm{dm}^{-3}\right)$} & & & $\left(\mathrm{mg} \mathrm{dm}^{-3}\right)$ & $\%$ & \\
\hline Safra 2013/2014 & 5,6 (água) & 2,8 & 0,7 & 0,24 & 5,2 & 33 & 2,3 & 73 \\
Safra 2014/2015 & $5,8\left(\mathrm{CaCl}_{2}\right)$ & 2,2 & 1,2 & 0,25 & 5,65 & 22,9 & 2,4 & 65 \\
\hline
\end{tabular}

Tabela 2. Ciclo e reação às doenças foliares de híbridos de milho.

\begin{tabular}{lccccc} 
Híbridos & $\begin{array}{c}\text { Empresa } \\
\text { Mantenedora }\end{array}$ & Ciclo & P.polysora & B. maydis & C.graminicola \\
& & & \\
\hline
\end{tabular}

\begin{tabular}{|c|c|c|c|c|c|}
\hline HS BRS 1040 & Embrapa & Precoce & $\mathrm{S}^{1}$ & $\mathrm{~S}$ & $\mathrm{~S}$ \\
\hline HS ATTACK & Syngenta & Precoce & $\mathrm{T}^{2}$ & $\mathrm{~T}$ & $\mathrm{~T}$ \\
\hline HD TRAKTOR & Syngenta & Precoce & $\mathrm{T}$ & $\mathrm{T}$ & $\mathrm{T}$ \\
\hline HD BM 2202 & Biomatrix & Precoce & $\mathrm{NE}^{3}$ & $\mathrm{NE}$ & $\mathrm{NE}$ \\
\hline HS 30F53YH & Dupont pionner & Precoce & $\mathrm{S}$ & $\mathrm{T}$ & $\mathrm{T}$ \\
\hline HS 2B710 & Dow agrosciences & Precoce & $\mathrm{T}$ & $\mathrm{T}$ & $\mathrm{T}$ \\
\hline HS AG7088 & Agroceres & Precoce & $\mathrm{T}$ & $\mathrm{T}$ & $\mathrm{T}$ \\
\hline HT 3H842 & Embrapa & Precoce & $\mathrm{NE}$ & $\mathrm{NE}$ & $\mathrm{NE}$ \\
\hline
\end{tabular}

${ }^{1}(\mathrm{~S}$ - Suscetível $),{ }^{2}(\mathrm{~T}$ - Tolerante $) \mathrm{e}^{3}(\mathrm{NE}$ - Não encontrado)

liar lesionada; $3=10 \% ; 4=30 \% ; 5=50 \% ; 6=70 \%$; $7=80 \% ; 8=90 \%$ e $9=100 \%$ de área foliar lesionada (Agroceres, 1996). Foi atribuída uma nota média de severidade de cada doença nas parcelas. Nas notas de 1 a 4, os híbridos foram classificados como de alta a mediana resistência. Nas notas 5 a 6 , foram classificados como de mediana suscetibilidade e com notas de 7 a 9, foram classificados como suscetíveis a altamente suscetíveis.

Em ambos os experimentos, as avaliações se iniciaram após o surgimento dos primeiros sintomas. As primeiras avaliações foram realizadas aos 77 e 60 dias após a semeadura (DAS), no primeiro e segundo experimentos, respectivamente. As avaliações foram realizadas em intervalo semanal. As notas de severidade em cada parcela foram transformadas em porcen- tagem de área foliar lesionada e utilizadas para calcular a AACPD, conforme Campbell e Madden (1990).

\section{Quantificação das respostas bioquímicas}

- Para as análises das respostas bioquímicas, foram utilizadas amostras de folhas dos híbridos 2B710 e AG7088PROX, considerados contrastantes para a reação (resistência ou suscetibilidade) à mancha-debipolares, a qual ocorreu com maior intensidade nos experimentos. Foram coletadas as folhas localizadas imediatamente abaixo da espiga, de três plantas distintas na linha central, com três repetições em cada tratamento, entre as fases R1 (polinização embonecamento) e R2 (grão bolha d'água). Após a coleta, as folhas foram acondicionadas em sacos de papel, identificados e colocadas em freezer a $-20{ }^{\circ} \mathrm{C}$ até o momento das análises. 

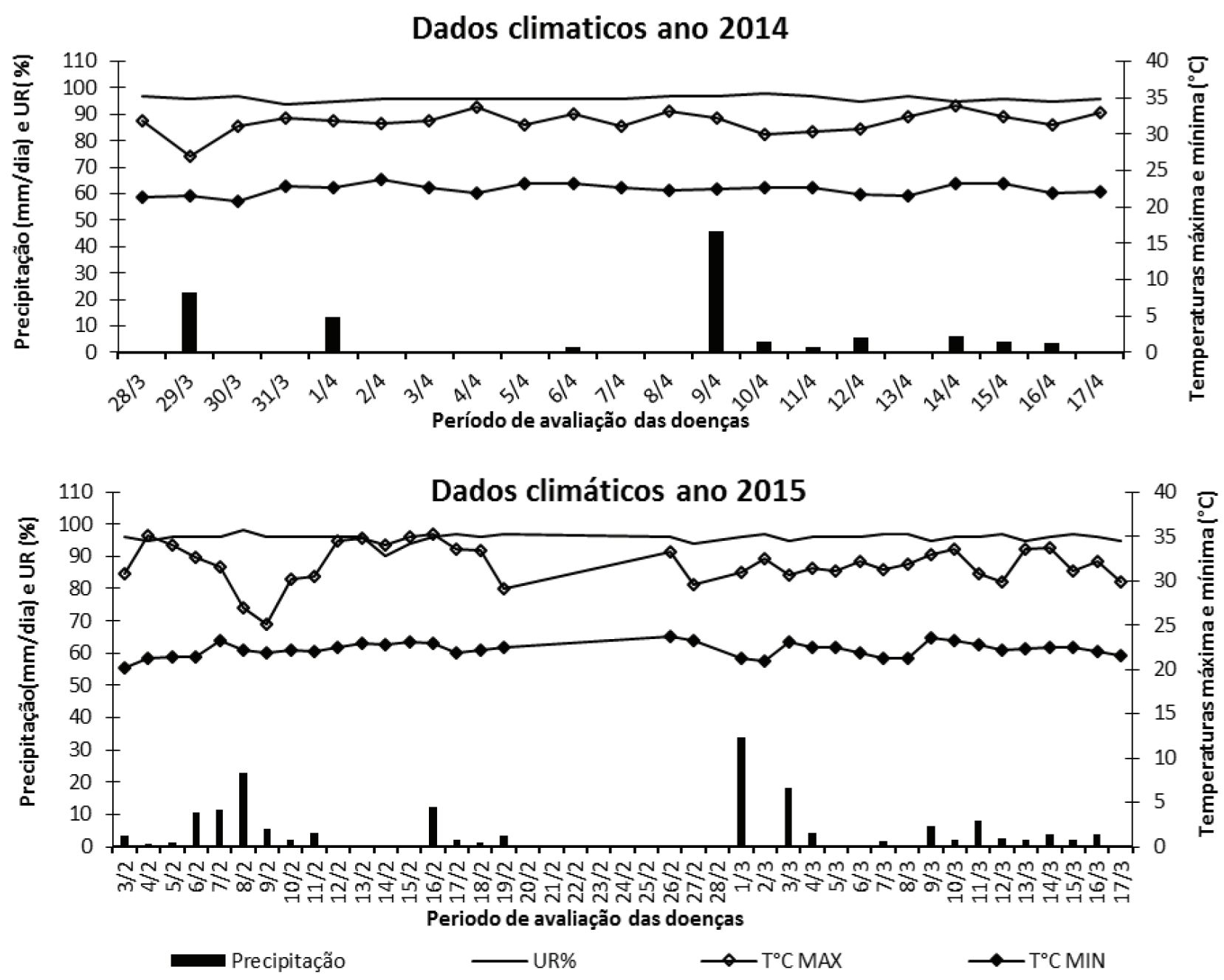

Figura 1 - Precipitação (mm), umidade relativa do ar (\%) e temperatura máxima e mínima $\left({ }^{\circ} \mathrm{C}\right)$ diárias, durante o período de condução do ensaio. Gurupi-TO, 2014/2015.

Para a quantificação dos teores das enzimas SOD e CAT, as amostras do tecido foliar foram maceradas em nitrogênio líquido para obtenção dos extratos. A atividade da SOD foi determinada conforme metodologia descrita por Gianopolitis e Ries (1977) e atividade da CAT foi determinada conforme Havir e McHale (1987). O decaimento da absorbância a 204 $\mathrm{nm}$ foi acompanhado em espectrofotômetro, durante cinco minutos, com leituras sucessivas a cada 30 segundos. A atividade das enzimas foi calculada com base no coeficiente de extinção molar de $36 \mathrm{M}^{-1} \mathrm{~cm}^{-1}$
(240 nm) para o $\mathrm{H}_{2} \mathrm{O}_{2}$ e expressa em $\mu$ mol $\mathrm{H}_{2} \mathrm{O}_{2} \mathrm{~g}^{-1}$ MF $\min ^{-1}$.

Os teores do aminoácido prolina foram determinados pelo método de Bates et al. (1973). Após obtenção do composto (reagentes ${ }_{+}$amostra de folha), o cromóforo foi aspirado com pipeta de Pasteur de vidro e utilizado para as leituras em espectrofotômetro a $520 \mathrm{~nm}$. O branco utilizado para zerar o aparelho continha apenas tolueno. A concentração do teor prolina foi calculada com base na equação da reta obtida por uma curva-padrão de prolina e expressa em mmol kg-1 
MF. Para determinar os teores de aminoácidos solúveis, utilizou-se a metodologia proposta por Yemm e Cocking (1955). Após a obtenção do composto, estas foram lidas em espectrofotômetro a $570 \mathrm{~nm}$, sendo que para o branco, o volume de extrato foi substituído por tampão citrato. A concentração de aminoácidos solúveis totais foi quantificada com base na equação da reta obtida pela curva-padrão de glicina e expressa em mmol kg-1 MF.

Análise de correlação e estatística - Foi determinado o coeficiente de correlação linear entre os dados dos compostos bioquímicos e a AACPD através da fórmula:

$$
r=\frac{n\left(\sum x \cdot y-\sum x \cdot \sum y\right)}{\sqrt{n\left[\sum x^{2}-\left(\sum x\right)\right] \cdot n\left[\sum y^{2}-\left(\sum y\right)\right]}}
$$

em cada dose de nitrogênio utilizada, para os híbridos 2B710 e o AG7088 PROX. Onde $r$ é o grau de correlação linear entre a variável X e Y, e $n$ o número de repetições de cada variável. Quanto mais próximo de -1 ou 1, maior o grau de relacionamento entre as duas variáveis; considera-se que em valores próximos de 1 há correlação linear positiva e em valores próximos de -1 existe uma correlação negativa.

Os dados de AACPD, massa de mil grãos, produtividade e compostos bioquímicos foram submetidos à análise de variância e as médias, quando necessário, foram comparadas entre si através do teste de Tukey a 5\% de probabilidade, com auxílio do software ASSISTAT 7.7 (Silva, 2015).

\section{Resultados e Discussão}

Durantes os dois anos de condução dos experimentos, as doenças predominantes foram manchade-bipolares, ferrugem-polissora e antracnose-foliar. Portanto, estas serão consideradas para as avaliações e análises no presente trabalho.

\section{Área abaixo da curva de progresso da doen-} ça - Houve diferença significativa para as doses (baixa e alta) de nitrogênio para a variável AACPD da mancha-de-bipolaris nos dois anos (Tabela 3). As maiores severidades da doença foram observadas nas parcelas submetidas às menores doses de $\mathrm{N}$, nos híbridos BRS1040, ATTACK, TRAKTOR, 2B710 e 3H842. Resultados semelhantes foram obtidos por Santos et al. (2013). Segundo os autores, a severidade da mancha-de-bipolaris variou conforme as doses de nitrogênio utilizadas e a genética dos híbridos, corroborando com os resultados encontrados nesse estudo.

Observando a resposta dos diferentes híbridos para cada categoria de dose (baixa ou alta), nota-se variação na resistência entre eles, sendo o BRS 1040 e o 2B710 os mais suscetíveis na condição de baixo e alto N. A reação do híbrido AG7088 não foi alterada pela variação das doses, o qual foi classificado como resistente. Observa-se que os genótipos variaram quanto a suscetibilidade à doença, independentemente das doses de nitrogênio aplicadas. Em trabalho semelhante, Santos et al. (2013) observaram que o genótipo AG7088 foi resistente à mancha-de-bipolaris, independentemente das doses de nitrogênio.

Para a ferrugem-polissora, os maiores valores de AACPD foram observados nas doses altas de N, nos híbridos ATTACK, TRAKTOR, BM 2202 e 30F53YH, nos dois anos (Tabela 3). Para os demais híbridos, não houve diferença significativa entre as doses de nitrogênio, quanto à severidade da ferrugem -polissora. Houve diferenças significativas entre os híbridos dentro de cada dose.

A maior severidade dos híbridos à ferrugem -polissora, nas maiores doses de $\mathrm{N}$, está de acordo com o relatado por Tomazela et al. (2006), que afirmam que a suplementação de plantas de milho com elevadas doses de nitrogênio pode ocasionar aumento 
Tabela 3 - Área abaixo da curva de progresso (AACPD) de doenças foliares do milho, sob adubação nitrogenada, $36 \mathrm{~kg} \mathrm{ha}^{-1}$ (baixo N) e $160 \mathrm{~kg} \mathrm{ha}^{-1}$ (alto N) (safra 2013/2014) e $40 \mathrm{~kg} \mathrm{ha}^{-1}$ (baixo N) e $180 \mathrm{~kg} \mathrm{ha}^{-1}$ (alto N) (safra 2014/2015), Gurupi-Tocantins, 2015.

\begin{tabular}{|c|c|c|c|c|}
\hline \multirow{3}{*}{$\begin{array}{c}\text { Doses de N } \\
\left(\mathrm{Kg} \mathrm{ha}^{-1}\right)\end{array}$} & \multicolumn{4}{|c|}{ Híbridos } \\
\hline & BRS 1040 & ATTACK & TRAKTOR & BM 2202 \\
\hline & \multicolumn{4}{|c|}{ Massa de mil grãos (g)* 2013/2014 } \\
\hline 160 & $341 \mathrm{Aa}$ & $304 \mathrm{ABa}$ & $290 \mathrm{Ba}$ & $339 \mathrm{Aa}$ \\
\hline 36 & $338 \mathrm{Aa}$ & $298 \mathrm{Ba}$ & $284 \mathrm{Ba}$ & $265 \mathrm{Bb}$ \\
\hline \multirow[t]{2}{*}{$\mathrm{CV} \%$} & \multicolumn{4}{|c|}{5,12} \\
\hline & \multicolumn{4}{|c|}{ Híbridos } \\
\hline \multirow{2}{*}{$\begin{array}{c}\text { Doses de N } \\
\left(\mathrm{Kg} \mathrm{ha}^{-1}\right)\end{array}$} & 30F53YH & 2B710 & AG7088 PROX & $3 \mathrm{H} 842$ \\
\hline & \multicolumn{4}{|c|}{ Massa de mil grãos (g) ${ }^{*} 2014 / 2015$} \\
\hline 180 & $309 \mathrm{Ba}$ & $357 \mathrm{Aa}$ & $286 \mathrm{Ca}$ & $300 \mathrm{BCa}$ \\
\hline 40 & $302 \mathrm{ABa}$ & $316 \mathrm{Ab}$ & $283 \mathrm{Ba}$ & $283 \mathrm{Ba}$ \\
\hline $\mathrm{CV} \%$ & \multicolumn{4}{|c|}{3,09} \\
\hline \multirow{3}{*}{$\begin{array}{l}\text { Doses de } \mathrm{N} \\
\qquad\left(\mathrm{Kg} \mathrm{ha}^{-1}\right)\end{array}$} & \multicolumn{4}{|c|}{ Híbridos } \\
\hline & 30F53YH & 2B710 & AG7088 PROX & $3 \mathrm{H} 842$ \\
\hline & \multicolumn{4}{|c|}{ Produtividade $\left(\mathrm{kg} \mathrm{ha}^{-1}\right)^{*} 2014 / 2015$} \\
\hline $180 \mathrm{~kg} \mathrm{ha}^{-1}$ & $7515 \mathrm{ABa}$ & $8127 \mathrm{Aa}$ & $6687 \mathrm{Ba}$ & $7302 \mathrm{ABa}$ \\
\hline $40 \mathrm{~kg} \mathrm{ha}^{-1}$ & $6894 \mathrm{Aa}$ & $6990 \mathrm{Ab}$ & $6102 \mathrm{Aa}$ & $6018 \mathrm{Ab}$ \\
\hline $\mathrm{CV} \%$ & & 6,11 & & \\
\hline
\end{tabular}

da severidade da ferrugem. Segundo os autores, a deficiência de nitrogênio desfavorece o ataque de patógenos biotróficos, pois estes necessitam de plantas bem supridas com nitrogênio para se estabelecerem. Altos teores de nitrogênio induzem a formação de tecidos jovens e suculentos que favorecem a colonização dos fungos. Dessa forma, o uso adequado de $\mathrm{N}$ é fundamental para a melhoria da resistência das plantas e redução dos níveis de doença nas lavouras.

Houve baixa severidade da antracnose foliar nos híbridos avaliados nas diferentes doses, porém, destacam-se os maiores valores em AACPD nas doses mais baixas para a maioria dos híbridos avaliados em ambas as safras (ATTACK, TRAKTOR, 30F53YH, 2B710 e AG7088 PROX). Esta condição foi semelhante ao que ocorreu para a mancha-de-bipolaris, demonstrando que, para microrganismos necrotróficos, o menor teor de $\mathrm{N}$ nos tecidos da planta favorece o desenvolvimento das doenças. Conforme Huber e Thompson (2007), os mecanismos envolvidos na relação patógeno-hospedeiro-nutriente ainda não são totalmente elucidados, porém, a nutrição equilibrada pode reduzir a severidade de algumas doenças, conferindo resistência fisiológica à planta, necessitando-se dessa maneira de estudos mais específicos para cada patógeno e em doses crescentes de nitrogênio em milho.

Comparando os híbridos dentro de cada dose, na safra 2013/2014, os maiores valores de AACPD foram observadas nos híbridos TRAKTOR, seguidos por BRS 1040 e BM 2202 na dose de baixo N (Tabela 3). Na dose de alto N, os híbridos BM 2202 e o BRS1040 foram os que apresentaram maior AACPD, de 10,9 e 9,37, respectivamente. Na safra 2014/2015, a severidade da doença também foi baixa, no entanto, maiores valores de AACPD podem ser observados 
na dose de baixo $\mathrm{N}$, com destaque para os híbridos 2B710 e 30F53YH. Na dose de alto $\mathrm{N}$, não foi observada diferença significativa entre os híbridos avaliados.

Massa de mil grãos e produtividade - $\mathrm{Na}$ safra 2013/2014, houve diferença estatística entre as doses de $\mathrm{N}$ apenas para o híbrido BM2202 para a variável massa de mil grãos (Tabela 4). Dentro de cada dose de $\mathrm{N}$, foi possível observar diferenças entre os valores da massa de mil grãos nos híbridos testados. Nas doses de baixo N, o híbrido BRS 1040 apresentou massa de mil grãos de $338 \mathrm{~g}$, diferindo-se dos demais híbridos. Na dose de alto N, o híbrido TRAKTOR, apresentou menor massa de mil grãos, diferindo-se estatisticamente dos demais.

Com relação à safra de 2014/2015, foi possível observar diferença nos valores da massa de mil grãos entre as doses de $\mathrm{N}$ avaliadas para o híbrido 2B710
(Tabela 4). Nos demais híbridos, as doses aplicadas não influenciaram nessa variável. Houve diferença estatística entre os híbridos, dentro de cada nível de adubação utilizada, sendo o híbrido 2B710 o que apresentou a maior massa de mil grãos nas duas doses de nitrogênio, 357 g e 316 g, respectivamente.

Observando numericamente essa variável nas duas safras, grãos mais pesados foram obtidos com as maiores doses de nitrogênio. A massa de mil grãos é considerada um dos componentes de rendimento do milho, sendo esperado que, em plantas submetidas a doses adequadas de nitrogênio, essa variável seja maior. No entanto, estatisticamente para a maioria dos híbridos avaliados, as doses de nitrogênio utilizadas neste estudo não influenciaram na massa de mil grãos, provavelmente porque os híbridos se diferenciam quanto à exigência nutricional e características genéticas (Floss, 2004).

Tabela 4 - Valores médios de massa de mil grãos (g), safras 2013/2014 e 2014/2015 e produtividade em kg ha $^{-1}$ de híbridos de milho, sob adubação nitrogenada (180 e $40 \mathrm{~kg} \mathrm{ha}^{-1}$ ), safra 2014/2015, município de GurupiTocantins, 2015.

\begin{tabular}{|c|c|c|c|c|}
\hline \multirow{3}{*}{$\begin{array}{l}\text { Doses de N } \\
\left(\mathrm{Kg} \mathrm{ha}^{-1}\right)\end{array}$} & \multicolumn{4}{|c|}{ Híbridos } \\
\hline & BRS 1040 & ATTACK & TRAKTOR & BM 2202 \\
\hline & \multicolumn{4}{|c|}{ Massa de mil grãos (g) ${ }^{*} 2013 / 2014$} \\
\hline 160 & $341 \mathrm{Aa}$ & $304 \mathrm{ABa}$ & $290 \mathrm{Ba}$ & $339 \mathrm{Aa}$ \\
\hline 36 & $338 \mathrm{Aa}$ & $298 \mathrm{Ba}$ & $284 \mathrm{Ba}$ & $265 \mathrm{Bb}$ \\
\hline $\mathrm{CV} \%$ & \multicolumn{4}{|c|}{5,12} \\
\hline \multirow{3}{*}{$\begin{array}{c}\text { Doses de N } \\
\left(\mathrm{Kg} \mathrm{ha}^{-1}\right)\end{array}$} & \multicolumn{4}{|c|}{ Híbridos } \\
\hline & 30F53YH & 2B710 & AG7088 PROX & $3 \mathrm{H} 842$ \\
\hline & \multicolumn{4}{|c|}{ Massa de mil grãos (g) ${ }^{*} 2014 / 2015$} \\
\hline 180 & $309 \mathrm{Ba}$ & $357 \mathrm{Aa}$ & $286 \mathrm{Ca}$ & $300 \mathrm{BCa}$ \\
\hline 40 & $302 \mathrm{ABa}$ & $316 \mathrm{Ab}$ & $283 \mathrm{Ba}$ & $283 \mathrm{Ba}$ \\
\hline $\mathrm{CV} \%$ & \multicolumn{4}{|c|}{3,09} \\
\hline \multirow{3}{*}{$\begin{array}{l}\text { Doses de N } \\
\qquad\left(\mathrm{Kg} \mathrm{ha}^{-1}\right)\end{array}$} & \multicolumn{4}{|c|}{ Híbridos } \\
\hline & 30F53YH & 2B710 & AG7088 PROX & $3 \mathrm{H} 842$ \\
\hline & \multicolumn{4}{|c|}{ Produtividade $\left(\mathrm{kg} \mathrm{ha}^{-1}\right)^{*} 2014 / 2015$} \\
\hline $180 \mathrm{~kg} \mathrm{ha}^{-1}$ & $7515 \mathrm{ABa}$ & $8127 \mathrm{Aa}$ & $6687 \mathrm{Ba}$ & $7302 \mathrm{ABa}$ \\
\hline $40 \mathrm{~kg} \mathrm{ha}^{-1}$ & $6894 \mathrm{Aa}$ & $6990 \mathrm{Ab}$ & $6102 \mathrm{Aa}$ & $6018 \mathrm{Ab}$ \\
\hline $\mathrm{CV} \%$ & \multicolumn{4}{|c|}{6,11} \\
\hline
\end{tabular}


A massa de mil grãos depende do potencial genético de cada cultivar, o qual determina o funcionamento do aparelho fotossintético das partes superiores da planta, da capacidade de transferência dos fotoassimilados para os grãos da duração do período de enchimento de grãos, das condições climáticas ocorridas durante a fase de enchimento de grãos (umidade e temperatura) e da ocorrência de moléstias (especialmente nas folhas e espigas/panículas) e pragas (Floss, 2004).

Dados da safra 2013/2014 não puderam ser coletados em razão de problemas que ocorreram na área experimental na fase final do experimento. Não houve diferença estatística para a produtividade de grãos entre as doses de nitrogênio nos híbridos 30F53YH e AG7088 PROX, avaliados na safra 2014/2015 (Tabela 4). Para os híbridos 2B710 e 3H842, foi observada diferença estatística entre a dose de alto e baixo $\mathrm{N}$.

O híbrido $2 \mathrm{~B} 710$ pode ser considerado tolerante às condições locais do estudo, pois, mesmo apresentando alta AACPD, ocasionada pela manchade-bipolaris, apresentou maior produtividade na dose de alto $\mathrm{N}$, demonstrando que a severidade da doença não é suficiente para minimizar o potencial produtivo deste híbrido em condições de adubação equilibrada. O híbrido 30F53YH demostrou ser o único suscetível à ferrugem-polissora na safra 2014/2015, no entanto, constatou-se que sua produtividade foi semelhante à dos demais, provavelmente porque a severidade elevada da doença foi observada nas fases finais do ciclo da cultura.

Sabe-se que, quando a ferrugem-polissora incide nas fases iniciais de desenvolvimento da cultura e as condições climáticas são favoráveis, a redução na produção é significativa. Porém, quando incide na fase final de desenvolvimento, praticamente não afeta a produção (Godoy, 2000). A produtividade dos híbri- dos avaliados neste trabalho provavelmente foi afetada também pela ocorrência de forte veranico na fase vegetativa e na floração. Esse fato explica, por exemplo, a baixa produtividade obtida do híbrido AG7088 PROX, pois mesmo apresentando severidade reduzida de doenças apresentou a menor produtividade, mesmo em condições de adubação nitrogenada elevada, demonstrando que os híbridos possuem níveis de tolerância ao estresse hídrico diferentes.

Respostas bioquímicas - Para o teor da enzima CAT, maiores teores foram observados na dose de baixo N no híbrido 2B710 e no híbrido AG7088 PROX na dose de alto $\mathrm{N}$, com valores de 1,5 e 1,21 $\mu \mathrm{mol} \mathrm{g} \mathrm{MF}^{-1}$, respectivamente. Quanto à SOD, não houve diferença significativa entre os híbridos e doses utilizadas (Figura 2b). As plantas em suas funções metabólicas normais produzem radicais livres derivados do processo respiratório e fotossintético (Éaux \& Toledano, 2007), e também são produzidos quando as plantas são submetidas a estímulos ambientais, mecânicos e outros, ou quando ocorre uma infecção por microrganismos que destroem os tecidos. Assim, as plantas protegem suas células desses efeitos citotóxicos com auxílio de enzimas antioxidantes como a SOD, CAT e outras (Soares \& Machado, 2007; Shen et al., 2010).

Com relação aos teores obtidos do aminoácido prolina, observou-se maior teor no híbrido 2B710 na dose de alto N, e para híbrido AG7088 PROX na dose

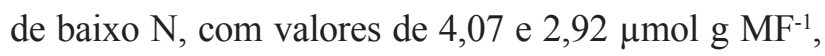
respectivamente (Figura 2c). Após reconhecimento do patógeno pela planta, ocorre a síntese de compostos antioxidantes que buscam diminuir os danos às células vegetais por causa da ação das espécies reativas de oxigênio, sendo a prolina um aminoácido que atua como um desses antioxidantes (Chen \& Dickman, 2005). Os teores de prolina observados neste estudo, 
A $\quad$ AG 7088 PROX $\square 2 B 710$

B

- AG 7088 PROX

2B710
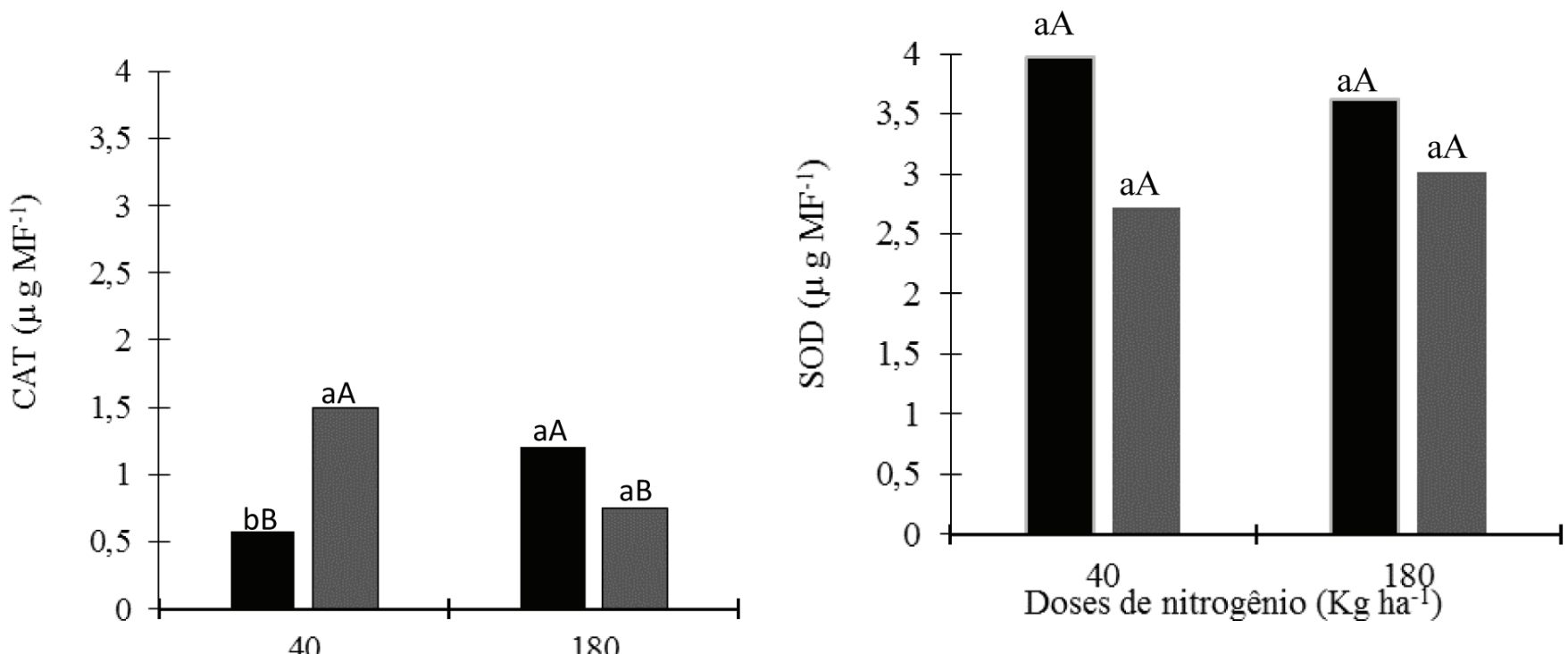

Doses de nitrogênio $\left(\mathrm{Kg} \mathrm{ha}^{-1}\right)$

C

- AG 7088 PROX

- 2B710

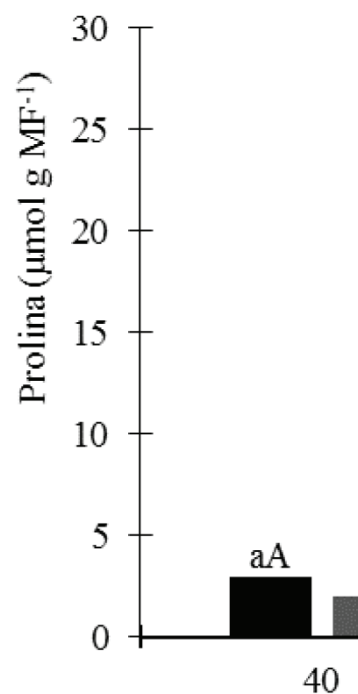

40

180

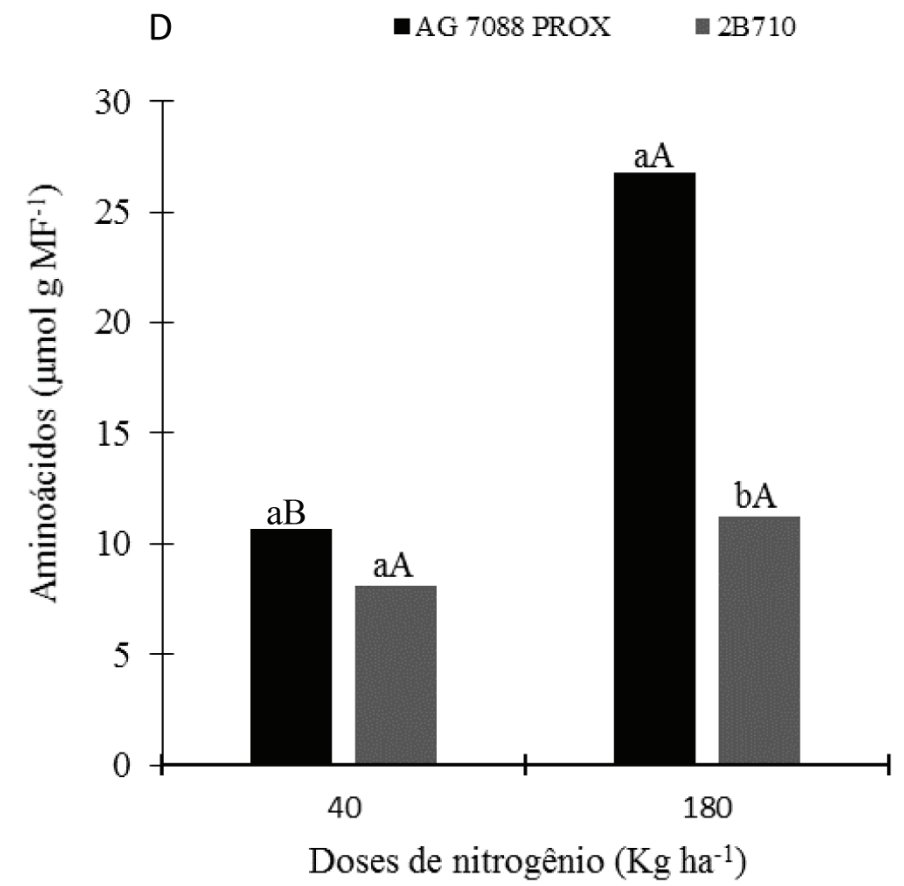

Figura 2 - Teores de: A - enzima catalase $\left(\mu \mathrm{g} \mathrm{MF}^{-1}\right) ; \mathrm{B}$ - enzima superóxido dismutase ( $\left.\mu \mathrm{g} \mathrm{MF}^{-1}\right)$; $\mathrm{C}$ aminoácido prolina ( $\mu \mathrm{mol} \mathrm{g} \mathrm{MF}^{-1}$ ) e $\mathrm{D}$ - aminoácido solúveis totais ( $\mu \mathrm{mol} \mathrm{g} \mathrm{MF}^{-1}$ ) em híbridos de milhos submetidos a doses de nitrogênio. Letras iguais, minúscula comparando híbridos e maiúsculas comparando as doses de nitrogênio, não diferem estatisticamente pelo teste de Tukey ao nível de 5\% de probabilidade. 
ao contrário do observado para a SOD e CAT, foram menores nas condições em que os híbridos sofreram maior estresse causado pela doença. Este resultado pode estar relacionado à redução da área foliar causada pela severidade da doença, pois este aminoácido é um importante constituinte básico de proteínas que fazem parte da estrutura da parede celular.

Nos teores de aminoácidos solúveis totais foram verificados maiores valores na dose de alto $\mathrm{N}$, nos dois híbridos avaliados, sendo $26,8 \mu \mathrm{mol} \mathrm{g} \mathrm{MF}^{-1}$ presente no híbrido AG 7088 PROX e 11,19 $\mu \mathrm{mol} \mathrm{g}$ $\mathrm{MF}^{-1}$ observado no híbrido 2B710. Na dose de baixo $\mathrm{N}$, não houve diferença entre os híbridos avaliados (Figura 2d). Este resultado é por causa, provavelmente, do maior suprimento de nitrogênio que leva ao aumento da concentração de aminoácidos no apoplasto e na superfície foliar (Malavolta, 2006). A influência da alta severidade da doença sobre esse composto foi maior no híbrido 2B710, com teores baixos quando comparado aos teores obtidos no híbrido AG7088PROX. Esse resultado pode estar relacionado à deterioração dos tecidos foliares e ao consumo desses compostos pelos patógenos. Neste caso, a variação na dose de nitrogênio utilizada influenciou de maneira significativa o híbrido AG7088PROX, uma vez que na menor dose os teores de aminoácido totais foram bastante inferiores.

Outro benefício que se pode atribuir aos aminoácidos, consiste na proteção das células de plantas com altas concentrações de amônio, provenientes de altas doses de adubação nitrogenada. Quando a planta possui um metabolismo equilibrado, em que a translocação de solutos está adequada, incluindo os minerais, aminoácidos e macroelementos como o nitrogênio, a suscetibilidade dela aos danos provocados pelos mais diversos estresses é amenizada, em vista do aumento da resistência sistêmica das plantas
(Campos, 2012).

No híbrido 2B710, a atividade da SOD foi correlacionada de modo positivo com a AACPD da mancha-de-bipolaris na dose de alto N. Já na dose de baixo N, verificou-se correlação fraca. Para a atividade da CAT e o teor de prolina, a correlação foi positiva entre as doses e a AACPD. Houve correlação positiva entre a dose de alto $\mathrm{N}$ e a AACPD para o teor de aminoácidos solúveis (Tabela 5). Para o híbrido AG7088 observa-se que para a maioria dos compostos nas duas doses o grau de relacionamento linear foi negativo em relação à $\mathrm{AACPD}$, como foi o caso da atividade da enzima SOD nas duas doses, CAT na dose de alto $\mathrm{Ne}$ aminoácidos solúveis nas duas doses de N. A prolina teve um grau de relacionamento positivo para a AACPD nas duas doses avaliadas (Tabela 5).

Embora não tenha ocorrido interação significativa para a SOD entre os tratamentos avaliados, percebe-se uma relação numérica entre a severidade da mancha-de-bipolaris e os teores elevados da enzima SOD. No híbrido AG7088PROX, que foi resistente à mancha-de-bipolares neste estudo, os teores de SOD foram maiores em relação ao híbrido 2B710, suscetível à mesma doença. Maiores teores de SOD já foram relatados em genótipos resistentes quanto à infecção por fungos, e esta situação pode ser uma estratégia da planta para restringir o desenvolvimento do patógeno pela ação antioxidante desta enzima (Ehsani-Moghaddam et al., 2006).

A correlação negativa observada entre a AACPD e os teores de aminoácido no híbrido AG7088PROX na dose de alto N pode ter ocorrido em função da menor severidade da doença apresentada, quando comparada a AACPD no híbrido 2B710. As plantas passam constantemente por diversas situações de estresses e conseguem modular resposta de defesa, como o exposto neste estudo, de forma a 
Tabela 5. Correlação linear entre os dados de área abaixo da curva de progresso da doença (AACPD) e compostos bioquímicos: enzimas catalase (CAT) e superóxido dismutase (SOD) em $\mu \mathrm{g} \mathrm{MF}^{-1}$; aminoácido prolina e aminoácido solúveis totais $\left(\mu \mathrm{mol} \mathrm{g} \mathrm{MF}^{-1}\right)$ em híbridos de milhos submetidos a doses de nitrogênio (40 e $\left.180 \mathrm{~kg} \mathrm{ha}^{1}\right)$.

\begin{tabular}{|c|c|c|c|c|c|}
\hline \multirow{2}{*}{$\begin{array}{c}\text { Doses de N } \\
\left(\mathrm{kg} \mathrm{ha}^{-1}\right)\end{array}$} & \multirow[t]{2}{*}{ AACPD } & SOD & CAT & Prolina & $\begin{array}{c}\text { Aminoácidos } \\
\text { Solúveis }\end{array}$ \\
\hline & & \multicolumn{2}{|c|}{$\left(\mu \mathrm{g} \mathrm{MF}^{-1}\right)$} & \multicolumn{2}{|c|}{$\left(\mu \mathrm{mol} \mathrm{g} \mathrm{MF}{ }^{-1}\right)$} \\
\hline \multicolumn{6}{|c|}{$2 B 710$} \\
\hline 40 & 2531 & 0,51 & 0,93 & 0,98 & 0,38 \\
\hline 180 & 2445 & 0,91 & 0,74 & 0,81 & 1,00 \\
\hline \multicolumn{6}{|c|}{ AG7088 PROX } \\
\hline 40 & 564 & $-0,72$ & 0,71 & 0,92 & $-0,99$ \\
\hline 180 & 584 & $-0,99$ & $-0,82$ & 0,98 & $-0,99$ \\
\hline
\end{tabular}

superar tais estresses e retornar ao metabolismo normal. Saber como as plantas se protegem é essencial para obter cultivares mais resistentes, almejando o aumento e a qualidade da produção (Soares \& Machado, 2007).

\section{Conclusões}

As doenças foliares mancha-de-bipolaris e a antracnose foram mais severas nas doses baixas de nitrogênio (36 e $40 \mathrm{Kg} \mathrm{ha}^{-1}$ ). A ferrugem-polissora foi mais severa quando as plantas foram submetidas à alta dose do nitrogênio (160 e $\left.180 \mathrm{Kg} \mathrm{ha}^{-1}\right)$. Os valores de massa de mil grãos não foram influenciados pelas diferenças nas doses mais alta e mais baixa. A produtividade dos híbridos 2B710 e 3 H842 foi maior na dose de $180 \mathrm{Kg} \mathrm{ha}^{-1}$. A catalase e a prolina obtiveram maior e menor atividade, respectivamente, onde ocorreu maior severidade da mancha-de-bipolaris nos híbridos 2B710 e AG7088PROX. Os aminoácidos foram encontrados em maiores quantidades nas doses altas de nitrogênio.

\section{Agradecimentos}

À Capes, Universidade Federal do Tocantins e Embrapa Milho e Sorgo pelo apoio financeiro e técnico.

\section{Referências}

AGROCERES. Guia de sanidade Agroceres. São Paulo, v. 2, p. 34-36, 1996.

BATES, L.; WALDREN, R. P.; TEARE, I. D. Rapid determination of free proline for water-stress studies. Plant and Soil, The Hague, v. 39, n. 1, p. 205-207, 1973.

CAMPOS, R. S. Aminoácidos protegem a planta do estresse. Revista Campo e Negócios, Uberlândia, v. 18, p. 1-3, 2012.

CANCELLIER, L. L.; AFFÉRRI, F. S.; CARVALHO, E. V.; DOTTO, M. A.; LEÃO, F. F. Eficiência no uso de nitrogênio e correlação fenotípica em populações tropicais de milho no Tocantins. Revista Ciência Agronômica, Fortaleza, v. 42, n. 1, p. 139-148, 2011.

DOI: 10.1590/S1806-66902011000100018. 
CARVALHO, D. O.; POZZA, E. A.; CASELA, C. R.; COSTA, R. V.; POZZA, A. A. A.; CARVAlHO, C. O. Adubação nitrogenada e potássica na severidade da antracnose em dois cultivares de milho. Revista Ceres, Viçosa, MG, v. 60, n. 3, p. 380-387, 2013.

DOI: 10.1590/S0034-737X2013000300011.

CARVALHO, E. V.; AFFÉRRI, F. S.; PELUZIO, J. M.; SANTOS, W. F.; BICUDO, S. J. Adaptability in fresh weight and grain production in maize genotypes in Tocantins, Brazil. Revista Ciência Agronômica, Fortaleza, v. 45, n. 4, p. 856-862, 2014.

DOI: $10.1590 /$ S1806-66902014000400025.

CAMPBELL, C. L.; MADDEN, L. V. Introduction to plant disease epidemiology. New York: John Wiley, 1990. $532 \mathrm{p}$.

CHEN, C.; DICKMAN, M. B. Proline suppresses apoptosis in the fungal pathogen Colletotrichum trifolii. Proceedings of the National Academy of Sciences of the United States of America, Washington, v. 102, n. 9, p. 3459-3464, 2005.

DOI: $10.1073 /$ pnas.0407960102.

ÉAUX, B.; TOLEDANO, M. B. Ros as signalling molecules: mechanisms that generate specificity in ROS homeostasis. Nature Reviews Molecular Cell Biology, London, v. 8, n. 10, p. 813-824, 2007.

DOI: $10.1038 / \mathrm{nrm} 2256$.

EHSANI-MOGHADDAM, B.; CHARLES, M. T.; CARISSE, O.; KHANIZADEH, S. Superoxide dismutase responses of strawberry cultivars to infection by Mycosphaerella fragariae. Journal of Plant Physiology, Stuttgart, v. 163, n. 2, p. 147-153, 2006.

DOI: 10.1016/j.jplph.2005.04.025.

FAGAN, E. B.; MEDEIROS, S. P.; MANFRON, P. A.; CASAROLI, D.; SIMON, J.; DOURADO NETO, D.; VAN LIER, Q.; SANTOS, O.; MÜLLER, L. Physiology of biologic fixation nitrogen in soybean. Revista da FZVA, Uruguaiana, v. 14, p. 89-106, 2007.
FLOSS, E. M. Fisiologia das plantas cultivadas: o estudo que está por trás do que se vê. 2. ed. Passo Fundo: Universitária, 2004. 536 p.

GIANOPOLITIS, C. N.; RIES, S. K. Superoxide dismutases: I. Occurrence in higher plants. Plant Physiology, Bethesda, v. 59, n. 2, p. 309-314, 1977.

GODOY, C. V. O clima que traz ferrugem. Revista Cultivar Grandes Culturas, Pelotas, n. 20, p. 20, 2000.

HAVIR, E. A.; MCHALE, N. A. Biochemical and developmental characterization of multiple forms of catalase in tobacco-leaves. Plant Physiology, Bethesda, v. 84, n. 2, p. 450-455, 1987.

HUBER, D. M.; THOMPSON, L. A. Nitrogen and plant disease. In: DATNOFF, L. E.; ELMER, W. H.; HUBER, D. M. (Ed.). Mineral nutrition and plant disease. Saint Paul: APS Press, 2007. p. 31-44.

KÖPPEN, W. Climatología con un studio de los climas de la tierra. México: FCE, 1948.

LIMA, L. M.; POZZA, E. A.; TORRES, H. N.; POZZA, A. A. A.; SAlgADO, M.; PFENNING, L. H. Relação nitrogênio/potássio com mancha de Phoma e nutrição de mudas de cafeeiro em solução nutritiva. Tropical Plant Pathology, Brasília, DF, v. 35, n. 4, p. 223-228, 2010.

MALAVOLTA, E. Manual de nutrição mineral de plantas. São Paulo: Agronômica Ceres, 2006. $638 \mathrm{p}$.

MENDES, M. C.; ROSSI, E. S.; FARIA, M. V.; ALBUQUERQUE, C. J. B.; ROSÁRIO, J. G. Efectos de fertilizantes nitrogenados y densidad de siembra del maíz en el Centro-Sur de Paraná. Pesquisa Aplicada \& Agrotecnologia, Guarapuava, v. 4, n. 2, p. 176-184, 2011.

QUEIROZ, A. M.; SOUZA, C. H. E.; MACHADO, V. J.; LANA, R. M. Q.; KORNDORFER, G. H.; SILVA, A. A. Avaliação de diferentes fontes e doses de nitrogênio na adubação da cultura do milho (Zea mays L.). Revista 
Brasileira de Milho e Sorgo, Sete Lagoas, v. 10, n. 3, p. 257-266, 2011.

DOI: 10.18512/1980-6477/rbms.v10n3p257-266.

SANTOS, G. R.; GAMA, F. R.; GONÇALVES, C. G.; RODRIGUES, A. C.; LEÃO, E. U.; CARDON, C. H.; BONIFACIO, A. Severidade de doenças foliares e produtividade de híbridos de milho em resposta à adubação nitrogenada. Revista Ceres, Viçosa, MG, v. 60, v. 4, p. 505-513, 2013.

DOI: 10.1590/S0034-737X2013000400009.

SANTOS, W. F.; AFFÉRRI, F. S.; PELUZIO, J. M. Eficiência ao uso do nitrogênio e biodiversidade em híbridos de milho para teor de óleo. Enciclopédia Biosfera, Goiânia, v. 11, n. 21, p. 216-225, 2015.

SOARES, A. M. S.; MACHADO, O. L. T. Defesa de plantas: sinalização química e espécies reativas de oxigênio. Revista Trópica-Ciências Agrárias e Biológicas, n. 1, n. 1, p. 9-19, 2007.

SHEN, X.; ZHOU, Y.; DUAN, L.; LI, Z.; ENEJI, A. E.; LI, J. Silicon effects on photosynthesis and antioxidant parameters of soybean seedlings under drought and ultraviolet-B radiation. Journal of Plant Physiology, Stuttgart, v. 167, n. 15, p. 12481252, 2010.

DOI: 10.1016/j.jplph.2010.04.011.

SILVA, F. A. S. Sistema de Assistência EstatísticaASSISTAT: versão 7.7 beta. Campina Grande: Universidade Federal de Campina Grande, 2015. Disponível em: < http://www.assistat.com>. Acesso em: 2 ago. 2015.

TOMAZELA, A. L.; FAVARIN, J. L.; FANCELLI, A. L.; MARTIN, T. N.; DOURADO NETO, D.; REIS, A. R. Doses de nitrogênio e fontes de $\mathrm{Cu}$ e Mn suplementar sobre a severidade da ferrugem e atributos morfológicos do milho. Revista Brasileira de Milho e Sorgo, Sete Lagoas, v. 5, n. 2, p. 192201, 2006.

DOI: 10.18512/1980-6477/rbms.v5n2p192-201.

YEMM, E. W.; COCKING, E. C. The determination of aminoacid with ninhydrin. Analyst, London, v. 80, p. 209213,1955 